Mots. Les langages du politique

\title{
Le xénisme français laïcité en finnois contemporain
}

\author{
Aïno Niklas-Salminen
}

\section{OpenEdition}

Journals

Édition électronique

URL : https://journals.openedition.org/mots/770

DOI : $10.4000 /$ mots. 770

ISSN : 1960-6001

\section{Éditeur}

ENS Éditions

\section{Édition imprimée}

Date de publication : 1 novembre 2006

Pagination : $37-47$

ISBN : 978-2-84788-099-1

ISSN : 0243-6450

\section{Référence électronique}

Aïno Niklas-Salminen, "Le xénisme français laïcité en finnois contemporain », Mots. Les langages du politique [En ligne], 82 | 2006, mis en ligne le 01 novembre 2008, consulté le 23 avril 2022. URL : http:// journals.openedition.org/mots/770; DOI : https://doi.org/10.4000/mots.770 


\section{Aïno Niklas-Salminen}

\section{Le xénisme français laïcité en finnois contemporain}

Il y a très peu de mots empruntés ${ }^{1}$ au français en finnois. Cependant, le mot laïcité fait son apparition de plus en plus souvent dans les médias et les conversations courantes en Finlande. La loi du 15 mars 2004 sur la laïcité à l'école en France a éveillé la curiosité des Finlandais, qui vivent dans un pays où la pleine liberté du culte date de 1923, et où l'Église évangélique luthérienne et la confession orthodoxe grecque ont le statut d'Églises d'État. $85 \%$ de la population appartiennent à l'Église évangélique luthérienne et seulement $1 \%$ à la confession orthodoxe grecque. $10 \%$ des Finlandais sont sans affiliation religieuse. Les autres confessions ne représentent donc qu'un pourcentage très faible ${ }^{2}$. Les enfants et les adolescents suivent un enseignement religieux à l'école. Les élèves qui font partie d'une confession particulière peuvent demander que cette confession leur soit enseignée, et ceux qui n'appartiennent à aucune confession étudient différentes philosophies si leurs parents ou leurs tuteurs en manifestent le désir.

Le mot laïcité est un xénisme : il est identifié comme mot étranger référant à une réalité étrangère. Le lexique finnois ne possède pas de terme pour désigner cette réalité notionnelle avec suffisamment de justesse et de précision. Ce manque pousse le locuteur à employer le mot français. Or, ce mot emprunté fait surgir une nouvelle unité sans recourir à des éléments lexicaux préexistants en finnois. Il s'agit d'un élément isolé qui est à la fois sémantiquement vide et morphologiquement immotivé. Quand le locuteur-encodeur utilise ce mot, il sait que l'allocutaire-décodeur ne le connait peut-être pas et qu'il doit l'expliciter dans son message. C'est souvent à l'aide d'une glose que le locuteur assure le contrôle des mots qu'il emploie.

Le corpus sur lequel est basé ce travail est formé de cinquante énoncés finnois contenant le xénisme français laïcité. Ces énoncés, repérés grâce au moteur de recherche «Google », ont été extraits des journaux, magazines et forums de discussions finlandais entre 2003 et 2005. Helsingin sanomat est le principal

1. Pour la définition des termes emprunt, xénisme et pérégrinisme, voir l'article de Sarah Leroy dans ce même volume.

2. www.info-finlande.fr

Université de Provence, aino.niklas-salminen@wanadoo.fr. 
journal quotidien en Finlande. II n'affiche pas de tendance politique particulière. Kristillinen kasvatus est un magazine en ligne publié par l'Église évangélique luthérienne et ayant pour but de contribuer à l'éducation de la jeunesse chrétienne. Kristillisdemokraattinen viikkolehti est le magazine hebdomadaire des chrétiens-démocrates. Ranskan uutiset.com, quant à lui, est un magazine en ligne qui s'adresse aux Finlandais vivant en France ou ayant un intérêt particulier pour la France. Ses articles traitent de sujets concernant les actualités politiques, économiques, culturelles et scientifiques. VapariForum, Näkökulma et Suomi 24 keskustelu sont des forums sans orientation religieuse ni politique, contrairement à Hourglass 2 Outpost, forum animé par les témoins de Jehovah. Les énoncés analysés sont donc extraits de sources très variées. Les auteurs des énoncés sont soit des journalistes, soit des internautes dont l'identité est difficile à cerner.

Toutes les occurrences de laïcité dans les énoncés étudiés sont glosées. On examinera les équivalences sémantiques employées par les locuteurs pour rendre ce xénisme compréhensible aux Finlandais. Les différentes tentatives d'explication montrent les difficultés éprouvées par les locuteurs pour saisir les contours de la notion. Les gloses nous permettront aussi d’observer les réactions des locuteurs à la fois envers le mot français laïcité et envers le concept qu'il représente. Ce xénisme notionnel semble être difficilement transposable en finnois, pour des raisons historiques et idéologiques. On s’interrogera également sur l'avenir de ce mot en finnois. Demeurera-t-il toujours un élément étranger référant à une réalité étrangère? Deviendra-t-il un pérégrinisme ou cessera-t-il un jour d'être perçu comme un élément étranger pour devenir un emprunt codifié?

\section{À la recherche d’équivalents finnois}

(1) maallisuus « le fait d'être séculier»

Ilman juhlavuottakin tämä "lä̈cité", maallisuus, nousee tavan takaa keskusteluun. (VapariForum, 24 janvier 2005)

Indépendamment de cet anniversaire, cette «laïcité », le fait d’être séculier, anime les discussions.

(2) tunnuksettomuus « le fait d'être non confessionnel »

Valtion virkailijoita ja työntekijöitä tämä lä̈cité eli tunnustuksettomuus koskee siitä päivästä alkaen, kun he astuvat toimeen. (Näkökulma, 17 décembre 2003)

Les fonctionnaires sont concernés par cette laïcité ou le fait d'être non confessionnel à partir du moment où ils entrent en fonction.

(3) maallisuusperiaate « le principe de sécularisation»

Laïcité eli maallisuusperiaattella tarkoitetaan uskonnon ja valtiovallan eroa toisistaan. (Helsingin Sanomat, 11 janvier 2005) 
La laïcité ou principe de sécularisation désigne la séparation entre la religion et les pouvoirs publics.

(4) maallisuuden periaate « le principe de la sécularisation»

Maallisuuden periaatteeseen (laïcité) nojaava laki kun kieltää huivit ja muut "huomiota herättävät uskonnolliset tunnukset" valtion kouluissa. (Helsingin Sanomat, 28 novembre 2004)

La loi basée sur le principe de laïcité interdit le port de foulards et autres « signes religieux voyants » dans les écoles publiques.

(5) ei-uskonnollisuus «non religiosité»

Ranskan valtio ja kirkko erotettiin toisistaan vuonna 1905 ja siitä lähtien ei-uskonnollisuus (laïcité) on valvonut perustuslain noudattamista. (Ranskan uutiset.com, 5 avril 2005)

L’État et l'Église ont été séparés en 1905 et depuis, la non religiosité (laïcité) veille à ce que la Constitution soit respectée.

Certains locuteurs proposent le mot maallisuus pour traduire laïcité. Ce substantif, qui se laisse traduire littéralement par «le fait d'être terrestre », a été formé à partir de l'adjectif maallinen («terrestre ») qui, de son côté, vient du substantif maa («terre»). Maallinen est le contraire de hengellinen «spirituel ». Parfois, maallisuus est accompagné de periaate ("principe»). Tunnuksettomuus est un autre substantif utilisé pour traduire le xénisme. Il vient de l'adjectif tunnukseton («non confessionnel»), qui est l'antonyme de tunnustuksellinen («confessionnel »). Ces équivalences par un lexème finnois unique proposent des approximations larges de laïcité; elles n'en cernent pas avec précision les contours sémantiques.

Les locuteurs recourent parfois à la périphrase pour tenter de mieux saisir le sens de laïcité. Certaines traductions insistent sur le principe de séparation ou sur la neutralité des relations entre le domaine religieux et l'État:

(6) kirkon ja valtion ero « la séparation entre l’Église et l’État»

Kirkon ja valtion ero toteutettiin lailla vuonna 1905 eli tänä vuonna tulee vuosisata tästä "ranskalaisesta keksinnöstä". (VapariForum, 24 janvier 2005)

La séparation entre l'Église et l'État a été édictée par une loi en 1905; autrement dit, cette « invention française » a cent ans cette année

(7) kirkon ja vation tiukka erottaminen « la stricte séparation entre l'Église et l'État » Ranskassa kirkon ja valtion tiukan erottamisen eli laïcité-periaatteen varjolla kielletään uskonnon symbolien käyttäminen koulussa. (Kristillinen kasvatus, janvier 2004)

En France, par la séparation stricte entre l’Église et l'État ou principe de laïcité, on interdit le port de symboles religieux à l'école.

(8) valtion ja kirkon erillisyys « la séparation entre l'État et l'Église»

Ranskassa laïcité (eli valtion ja kirkon erillisyys) on niin voimakas periaate, että tuo laki tuntuu useimmista luonnolliselta. (Suomi 24 keskustelu, 22 décembre 2003) 
En France, la laïcité (ou séparation entre l'État et l'Église) est un principe tellement fort que les gens considèrent cette loi comme naturelle.

(9) valtion ja uskontojen neutraalit välit « la neutralité des relations entre l’État et les religions »

Tutkimus tarkastelee uskonnon paikkaa ranskalaisessa yhteiskunnassa määrittelevää laïcité-periaatetta, jolla tarkoitetaan valtion ja uskontojen neutraaleja välejä. (Helsingin Sanomat, 12 mai 2003)

L'étude examine le principe de laïcité, qui détermine la place de la religion dans la société française et qui signifie la neutralité des relations entre l’État et les religions.

D'autres mettent l'accent sur la séparation entre religion et système scolaire ou encore entre, d'une part, l'Église et, d'autre part, l'administration, le système scolaire et la politique :

(10) uskonto ja koululaitos on erotettu toisistaan « la religion et le système scolaire ont été séparés l'une de l'autre »

Ranskassa uskonto ja koululaitos on erotettu toisistaan (principe de laïcité). (Ranskan uutiset.com, 2 septembre 2004)

En France, la religion et le système scolaire ont été séparés l'un de l'autre.

(11) uskonnon täydellinen erottaminen hallinnosta, koulujärjestelmästä ja politiikasta « la séparation complète entre la religion et l'administration, le système éducatif et la politique»

Senegalin koulujärjestelmä luotiin siirtomaa-aikan ranskalaisen mallin mukaan. Sen kulmakiviä olivat ja ovat edelleen ranskan kieli ja ranskalaisille niin tärkeä laïcité eli uskonnon täydellinen erottaminen hallinnosta, koulujärjestelmästä ja politiikasta. (VapariForum, 24 janvier 2005)

Le système scolaire sénégalais a été créé durant la colonisation selon le modèle français. Les points importants de ce système étaient et demeurent la langue française et la laïcité si chère aux Français, c'est-à-dire la séparation totale entre la religion et l'administration, le système scolaire et la politique.

Certains locuteurs disent qu'il s'agit d'une loi, d'autres éprouvent le besoin de gloser une traduction par une autre traduction :

(12) maallisuuden periaatteeseen nojautuva laki « une loi basée sur le principe de sécularisation » (voir supra ex. 4)

maallisuus eli siis ei-uskonnollisuus (Ranskan uutiset.com, 12 avril 2004)

Le fait d'être séculier ou, autrement dit, la non religiosité.

Depuis 2004, beaucoup de Finlandais associent le concept de laïcité à l'interdiction de porter le foulard. Ainsi le mot composé huivilaki «la loi du foulard» est fréquemment proposé pour traduire laïcité :

(13) Sieppaajat vaativat Ranskan kumoamaan vasta voimaan tulleen "huivilain" (la loi sur la laïcité), joka kieltää näkyvien uskonnollisten tunnusmerkkien käytön koulussa. (Ranskan uutiset.com, 2 septembre 2004) 
Les ravisseurs exigent que la France supprime la loi du foulard (la loi sur la laïcité) qui interdit le port de signes religieux voyants à l'école.

Comparons ces gloses à la définition donnée par le Trésor de la langue française:

A. - Principe de séparation dans l'État de la société civile et de la société religieuse.

B. - Caractère des institutions, publiques ou privées, qui, selon ce principe, sont indépendantes du clergé et des Églises; impartialité, neutralité de l'État à l'égard des Églises et de toute confession religieuse. Principe de séparation de la société civile et de la société religieuse, l'État n'exerçant aucun pouvoir religieux et les Églises aucun pouvoir politique.

On peut constater que, dans la langue d'origine, le concept de laïcité correspond à un principe de séparation plus général que les applications particulières auxquelles pensent certains locuteurs finlandais.

Ces différentes traductions semblent démontrer que les locuteurs ont du mal à trouver, même en passant par des périphrases, l'équivalent exact du mot laïcité en finnois. Ces difficultés sont rencontrées aussi bien par les auteurs des énoncés extraits des journaux et magazines que par les internautes des forums. S'agit-il d'un ancrage résolu dans la vie temporelle? Ou s'agit-il plutôt d'une séparation entre le domaine religieux et l'État ou entre l'Église et l'école? Les expressions proposées ne possèdent pas tous les sèmes nécessaires pour saisir le sens juste de la réalité désignée. Le cadre historique, idéologique et politique de la Finlande est très différent de celui de la France.

En effet, la Finlande est un petit pays très homogène, aussi bien au niveau culturel que religieux. La proportion d'étrangers dans la population finlandaise est parmi les moins élevées d'Europe ( $2 \%)$. Les groupes les plus importants sont constitués par les Russes, les Estoniens, les Suédois, les Somaliens et les Irakiens. La Finlande a accueilli des étrangers pour des raisons diverses: actions humanitaires, regroupement familial, besoin de main-d'œuvre, accueil d'étudiants. Ce pays, qui faisait partie de la Suède jusqu'au $19^{\mathrm{e}}$ siècle et qui fut constitué, en 1809, en un grand-duché dépendant de la Russie, a obtenu son indépendance en 1917 seulement.

L'Église a souvent été une alliée politique des Finlandais dans sa difficile conquête de l'indépendance. Par exemple, la Guerre d'Hiver contre l'URSS (19391940) a été marquée par une lutte pour la défense du triple principe « famille, foi, patrie ». La volonté de défendre son pays avait ainsi des tonalités fortement religieuses. L'indépendance administrative et financière de l'Église est aujourd'hui considérable: les paroisses tiennent les registres d'état civil de la population et le conseil familial, ainsi que l'action en faveur de la jeunesse, font partie des tâches de l'Église. C'est par le culte, les divers offices et rites religieux que l'Église touche le mieux ses membres; 89\% des enfants sont baptisés, $90 \%$ des adolescents prennent part à la préparation en vue de la confirmation et sont 
confirmés, 80 \% des couples se marient à l'église. Le concept de laïcité semble très loin des préoccupations des Finlandais. ${ }^{3}$

\section{Une traduction accompagnée d'un commentaire}

Parfois le locuteur ne se satisfait pas de la simple traduction : il se lance dans des explications plus étendues sur le référent. L'extrait qui suit, par exemple, met en relief des évènements historiques qui aident à saisir le sens de laïcité :

(14) Ranskassa on suuresta vallankumouksesta saakka (pieniä taukoja lukuunottamatta) ollut vallalla n.k. laïcité-periaate, jonka mukaan maallisen valtion on oltava uskonnollisesti täysin neutraali, eikä mitään uskontoa saa julkisuudessa suosia. Viimeaikainen kohuttu koulujen huivikielto (joka tosiasiassa koskee kaikkia uskonnollisia tunnuksia, kuten ristejä ja Daavidin tähtiä) on hyvä esimerkki laïcité-periaatteesta. Käytännössä laïcité-periaate on saanut usein voimakkaan uskonnon- ja eritoten kristinuskon vastaisia piirteitä. Jopa Ranskassa vallitsevan katolisen kirkon toimintaa on periaatteen nojalla rajoitettu voimakkaasti. Vielä paljon raskaammin on laïcité-periaate koskenut pieniin protestanttisiin yhteisöihin sekä Jehovan todistajien tapaisiin reunaprotestanttisiin yhteisöihin. (Hourglass2 Outpost, 9 mai 2004) En France, depuis la grande Révolution (malgré quelques intermèdes), règne un principe de laïcité selon lequel l'État doit être totalement neutre par rapport à la religion, et aucune religion ne doit être favorisée ouvertement. L'interdiction de porter le foulard à l'école, qui a récemment défrayé la chronique (interdiction qui concerne en fait tous les signes religieux, comme les croix et les étoiles de David), est un bon exemple du principe de laïcité. En réalité, ce principe semble parfois agir contre la religion, surtout la religion chrétienne. Ce principe a même restreint les activités de l'Église en France. Le principe de laïcité a touché encore davantage les petites communautés protestantes ainsi que celles qui se trouvent aux frontières du protestantisme, telles les témoins de Jehovah.

Cette explication, extraite du forum animé par les témoins de Jehovah, est relativement traditionnelle, mais on peut aussi rencontrer des interprétations plus originales qui se placent plutôt du point de vue sociologique. La citation suivante, trouvée dans le magazine hebdomadaire des chrétiens-démocrates, par exemple, se focalise sur la structure générale de la société :

(15) Valtionkirkko on ajat sitten lähtenyt palvelemaan korruptoituneiden ja poliittisesta vallasta pitävien patriarkkojen etua, ja iloinen, moniarvoinen uskonnollisuus on unohtunut ajat sitten - toisena esimerkkinä on Ranskan tiukka laïcité, kirkon ja valtion ero, jossa yhden laimean kaikille sopivan yhteisön sijaan on monenmonia heterogeenisiä pieniä uskontokuntia : osa iloisia ja värikkäitä railakkaine gospeljumalanpalveluksineen, osa hiljaisia ja synkkiä. (Kristillisdemokraattinen viikkolehti, 28 mai 2005)

3. www.info-finlande.fi 
L’Église officielle a commencé il y a déjà longtemps à servir les intérêts des patriarches corrompus avides de pouvoir et la pratique religieuse joyeuse et pluraliste a été oubliée - un autre exemple est la laïcité stricte de la France, la séparation entre l'Église et l'État, où, à la place d'une communauté terne et fade qui convient à tout le monde, il existe de petites religions hétérogènes. Les unes sont gaies et bigarrées avec leurs gospels, les autres silencieuses et austères.

Les explications suivantes, tirées d'un forum sans orientation politique ni religieuse, se concentrent sur les comportements sociaux de l'individu :

(16) Ranskan kielen sana laïcité, jota koko ajan käytetään, on hieman vaikea kääntää, koska käsitteen sisältö on Ranskassa valtion ja uskontojen erottamisen pitkällisen historian seurauksena enemmän kuin «tunnustuksettomuus», jota se pohjimmiltaan tarkoittaa, mutta lisäksi siinä on ajatus yksityisen ja julkisen puolen erottamisesta toisistaan, toisin sanoen yksityisesti voi tunnustaa ja harjoittaa uskontoa, mutta valtion virassa tai koulussa on pitäydyttävä tunnustuksettomuudessa. (Näkökulma, 17 décembre 2003)

Le mot du lexique du français laïcité, qui est employé constamment, est assez difficile à traduire parce que le contenu du concept dépasse le sens strict du terme, et exprime une idée de séparation entre vie privée et vie publique; autrement dit, on peut pratiquer une religion d'une façon individuelle, mais lorsqu'on travaille pour l'État ou pour l'école, on est contraint d'être laïc.

Plusieurs précisions sont données pour clarifier la notion de laïcité dans les énoncés étudiés. Certains locuteurs expliquent que la laïcité interdit le port de foulards et autres signes voyants dans les écoles publiques. Pour d'autres, ce concept signifie que la France se transforme en une société multiculturelle et tolérante ou que l'État ne reconnait pas les minorités religieuses et ethniques et ne recense pas leurs membres. Certains énoncés précisent que la religion ne devrait pas s'occuper des affaires de la société laïque et vice versa.

Comme on peut le constater dans d'autres cas d'emprunt, le mot venu d'ailleurs combine souvent explications et commentaires axiologiques ${ }^{4}$. La glose peut se caractériser par une orientation évaluative envers le référent présenté en portant sur celui-ci un jugement positif ou négatif. Elle peut avoir comme but, par exemple, de faire assimiler ou, au contraire, de rejeter le référent. Il arrive que les explications contiennent des commentaires axiologiques, comme dans les gloses suivantes:

ranskan tiukka laïcité « la laïcité stricte de la France » (ex. 15 supra)

ranskalaisille niin tärkeä laïcité « la laïcité si chère aux Français » (ex. 11 supra)

tämä ranskalainen keksintö « cette invention française » (ex. 6 supra)

Agacement, moquerie ou scepticisme, le locuteur marque alors une certaine distance par rapport au mot laïcité. Mais la plupart du temps, ceux qui emploient

4. Voir par exemple A. Steuckardt dans ce même volume. 
ce xénisme dans leurs énoncés semblent être animés par la curiosité envers ce phénomène français. On a l'impression qu'ils essaient de comprendre le sens du mot emprunté et de l'expliquer aux autres. Ils ne développent pas d'arguments pour le faire accepter en finnois. Ils n'en développent pas non plus pour le rejeter. Les réactions des locuteurs envers laïcité ne seraient sans doute pas aussi neutres si la réalité désignée par ce mot était en voie d’intégration en Finlande. Or, les Finlandais, très attachés à leur système qui unit le domaine religieux et l'État, ne semblent pas avoir l'intention d'adopter le concept de laïcité dans leur pays.

Les réactions des locuteurs envers le mot laïcité ne seraient sans doute pas non plus aussi neutres si les mots français étaient considérés comme une menace pour le finnois. Les mots empruntés au français en finnois se trouvent surtout dans des domaines qui touchent la mode, la coiffure, la cuisine ou la culture. Parfois, la réalité désignée ne possède pas de nom en finnois et cette lacune conduit à employer le nom en français. Parfois encore, la réalité désignée possède un nom en finnois, mais l'emploi du mot français semble aider à saisir l'authenticité de ce référent en lui donnant plus de précision et de force que son équivalent en finnois. Il arrive aussi que le référent possède un nom en finnois, mais l'emploi du mot français semble être plus élégant, plus sérieux ou, au contraire, plus amusant que son équivalent en finnois.

Comme les emprunts au français sont peu nombreux en finnois, ceux-ci, au lieu d'être rejetés, sont plutôt bien accueillis par les locuteurs finlandais. Il en va différemment avec les emprunts à l'anglais. L'anglicisme est quantitativement dominant parmi les mots étrangers récemment implantés en finnois. Un grand nombre d'anglicismes peuvent sembler contestables dans la mesure où ils ne sont pas nécessaires. Le prestige des États-Unis, leur puissance économique et leur avance technoscientifique suscitent un flot d'emprunts même lorsque le finnois possède déjà le mot qui convient. Ainsi l'anglicisme, qui relevait autrefois d'un snobisme des classes aisées, exerce aujourd'hui une pression qui touche toutes les classes de la société, et largement les adolescents.

Le suédois est la deuxième langue officielle en Finlande. Il est intéressant de réfléchir rapidement sur les gloses du mot laïcité dans les énoncés produits par les suédophones vivant en Finlande. On y trouve les mêmes types de gloses que dans les énoncés des finnophones :

(17) «Laïcité » : detta begrepp innebär ett starkt åtskiljande mellan en religiös och en sekulärsfär. (Diakonivetenskapliga institutet, 4 juin 2004)

"Laïcité » : cette notion signifie qu'il y a une forte séparation entre la sphère religieuse et la sphère séculière.

(18) Frankrike har ju haft en lång tradition av att betona statens konfessionslöshet den så kallade laïcité-doktrinen. (Näkökulma, 11 mars 2004)

La France souligne traditionnellement la non-confessionnalité de l'État - ce qu'on appelle la doctrine de laïcité. 
(19) Denna debattställer viktiga frågor om värderingar djupt rotade i den franska folksjälen : respect för medborgerliga rättigheter, religionsfrihet och framför allt « laïcité », ett uttryck son bäst översätts till «åtskillnad mellan kyrka och stat». (Offensiv, 19 février2004)

Ce débat soulève des questions importantes sur l'évaluation de la mentalité nationale française enracinée en profondeur : le respect des droits civiques, la liberté du culte et avant tout la « laïcité », une expression qu'on traduit le mieux par « distinction entre l’Église et l’État ».

Les différentes traductions proposées pour le mot laïcité («forte séparation entre la sphère religieuse et la sphère séculière », "non-confessionnalité »), ainsi que les commentaires sur les traductions (ex. expression qu'on traduit le mieux par "distinction entre l'Église et l'État », dans l'extrait précédent) soulignent bien les difficultés éprouvées par les locuteurs suédophones pour saisir les contours de la notion.

Il n'en est peut-être pas tout à fait de même dans les énoncés des suédophones vivant en Suède. Ce pays est resté longtemps ethniquement homogène. Sa démographie a connu une mutation radicale au cours des cinquante dernières années avec l'afflux de centaines de milliers d'immigrants venus de toutes les régions du monde. Actuellement, environ $20 \%$ de sa population est d'origine étrangère. En peu de temps, l'immigration a apporté des changements spectaculaires et fait de la Suède un pays multiculturel et cosmopolite. En janvier 2000, l’Église de Suède, luthérienne et évangélique, a coupé ses liens de dépendance avec l'État et elle se trouve aujourd'hui sur un pied d'égalité avec les autres Églises. Chez les immigrés, l'Église catholique romaine et les Églises orthodoxe et orientale sont les plus importantes. Le nombre de musulmans a fortement augmenté, des mosquées sont construites en divers points du pays ${ }^{5}$. Sans avoir mené sur les gloses de laïcité en suédois une enquête aussi approfondie que sur ses gloses en finnois, j'ai pu cependant rencontrer dans la presse suédoise l'expression d'un point de vue nettement critique sur ce concept, comme en témoigne le passage suivant :

(20) Frankrike står inför en konfrontation mellan historiska ideal från franska revolutionen om statens separation från kyrkans makt (även kallad laïcité eller det konfessionslösa samhället) och ett mångkulturellt samhälle där intergrationen $i$ verkligheten inte alltid följt vackra ideal. Instället känner sig alltfler andra och tredje generationens invandrare exkluderade från det moderna franska samhället. Därför söker de sin identitet på annat håll, i sin kulturella och religiösa tillhörighet, vilka ibland tar sig extrema uttryck i fundamentalism och extremism. (Stockholms Fria Tidning, 12 février 2004)

La France se trouve devant une confrontation entre un idéal historique issu de la Révolution française - la libération de l'État vis-à-vis du pouvoir de l'Église (que l'on appelle laïcité ou société non-confessionnelle) et une société multiculturelle où

5. http://www.eu2001.se 
l'intégration, en réalité, ne correspond pas toujours aux beaux idéaux. De plus en plus d'immigrés de la deuxième ou de la troisième génération se sentent exclus de la société française moderne. C'est pour cela qu'ils cherchent leur identité ailleurs, dans leur appartenance culturelle et religieuse, ce qui parfois se manifeste d'une façon excessive par le fondamentalisme ou l'extrémisme.

La laïcité est ici regardée comme un de ces «beaux idéaux » sans référence dans la réalité sociale. Les particularités liées aux contextes socioculturels, politiques, historiques ou idéologiques des pays des langues emprunteuses peuvent changer considérablement le discours des locuteurs, aussi bien sur le mot laïcité que sur le concept de laïcité. La Finlande, pays ethniquement très homogène, n'a peut-être pas la même vision des choses que son voisin cosmopolite et multiculturel.

\section{Spéculations sur l’avenir du xénisme laïcité en finnois}

Le mot emprunté a toutes les chances de s'introduire dans l'usage de l'ensemble des locuteurs s'il est considéré comme utile, si son intégration dans le système de la langue ne pose pas trop de problèmes, si le statut socioculturel de la langue-source par rapport à la langue-cible est réputé prestigieux, etc. Progressivement, il prend sa place dans la structure de la langue et établit des relations avec les unités préalablement existantes. Le succès des emprunts dépend donc considérablement du jugement collectif des sujets parlants sur les civilisations dont ils témoignent.

Selon Josette Rey-Debove (1997, p. 283), le mot étranger est employé d'abord "timidement ", avec des caractères italiques, des guillemets ou des commentaires, par quelques personnes, puis sans précautions et plus ou moins massivement. Le mouvement de codification va de l'appartenance au lexique total ${ }^{6}$ vers l'appartenance au lexique commun7 . Les mots étrangers qui font partie du lexique commun sont codifiés. En revanche, les mots étrangers connus d'une partie seulement des usagers sont plus ou moins codifiés selon leur fréquence.

Le mot étranger se trouve d'abord hors code; il est signalé comme nom étranger d'une réalité étrangère. C'est la relation métalinguistique entre deux signes qui assure la compréhension de l'énoncé : le mot emprunté est d'abord accompagné du mot (ou de la périphrase synonymique) de la langue emprunteuse qui le glose. Quand le mot étranger n'est plus mis en relation avec le mot de la langue emprunteuse, l'énoncé est jugé compréhensible par l'encodeur : à ce stade, on estime que l'emprunt est codifié.

On peut se demander quel sera l'avenir du mot français laïcité en finnois.

6. Lexique total : réunion de tous les idiolectes.

7. Lexique commun : intersection de tous les idiolectes. 
On note qu'il n'apparaissait que très rarement dans les médias et les conversations courantes en Finlande avant 2004. Il est devenu à la mode avec la loi sur la laïcité récemment votée en France. Il est toujours glosé dans les énoncés étudiés et la variété des gloses qui l'accompagnent montre la difficulté de saisir le concept. Sera-t-il adopté par le finnois ou sera-t-il délaissé avec l'oubli des discussions nourries par cette fameuse loi ?

Plusieurs arguments semblent plaider en faveur de l'éventuelle adoption du mot laïcité en finnois. En effet, on a pu constater que les locuteurs finlandais éprouvent le besoin d'introduire ce mot dans leurs discours pour combler une lacune lexicale et désigner d'une façon efficace le référent typiquement français. On peut noter également que ce mot est facile à prononcer pour les Finlandais; cet aspect pourrait faciliter son intégration dans le système formel de la langue. En outre, les emprunts au français ne semblent pas être considérés comme une menace pour le finnois. Bien au contraire, les mots français semblent jouir d'un certain prestige chez les Finlandais. La loi sur la laïcité a été votée en France, mais les réflexions sur le concept de laïcité ne seront certainement pas oubliées par les locuteurs dans un monde moderne où coexistent et s'affrontent parfois différentes religions. Tous ces critères semblent soutenir la lexicalisation de l'emprunt laïcité en finnois.

Cependant les Finlandais, vivant en harmonie avec leur système confessionnel, ne semblent pas actuellement avoir l'intention d'adopter le concept de laïcité dans leur pays. Éprouveront-ils le besoin d'intégrer le mot si le référent qu'il désigne n'est pas lui-même intégré ? II nous manque le recul du temps pour savoir si le mot laïcité n'aura fait qu'une apparition sans lendemain dans la langue finnoise, s'il se lexicalisera tout en demeurant un xénisme, ou s’il deviendra un jour un emprunt codifié.

\section{Références}

NIKLAS-SALMINEN A., 2003, "Les emprunts et la glose», A. Steuckardt et A. NiklasSalminen éd., Le mot et sa glose, Aix-en-Provence, Publications de l'Université de Provence, p. 57-72.

REY-DEBOVE J., 1998, La linguistique du signe, Paris, Armand Colin, $303 \mathrm{p}$.

—1997, Le métalangage, Paris, Armand Colin, $401 \mathrm{p}$.

STEUCKARDTA. et NIKLAS-SALMINEN A. éd., 2005, Les marqueurs de glose, Aix-en-

Provence, Publications de l'Université de Provence, $326 \mathrm{p}$.

www.eu2001.se

www.info-finlande.fr 